\title{
Effects of multi-sequence combination forces on creep characteristics of bales during wheat harvesting
}

\author{
Zhong Tang*, Yaquan Liang, Ben Zhang, Meiling Wang, Hao Zhang, Yaoming Li \\ (Key Laboratory of Modern Agricultural Equipment and Technology of Ministry of Education, Jiangsu University, \\ Zhenjiang 212013, Jiangsu, China)
}

\begin{abstract}
During the baling operation, the wheat stalks are subjected to various mechanisms in the baler and the main form is compression. After the wheat stem is forced by a combination of the threshing cylinder, it needs to be formed under the action of straw baler and meet transport requirements. This paper mainly studies the properties of wheat stalks when baling, and proposes the application of the creep after-effect theory during the baling process. The tension-compression tester was used to perform a $50 \mathrm{~mm}$ stalk mechanical test, $50 \mathrm{~mm}$ stalk static pressure test, $35 \mathrm{~mm} \times 40 \mathrm{~mm} \times 50 \mathrm{~mm}$ stalk module static pressure test and bale static pressure test. The measured elastic modulus of the stem sample was 7.59 MPa, and the elastic modulus of the inner core of the stem was 8.24 MPa. The return curve of the single stalk and the bale is consistent with the initial creep and steady-state creep in the creep after-effect theory. A logarithmic function was used for fitting of the first stage with coefficient of determination $R^{2}=0.8364$, and a linear function was used for fitting of the second stage with coefficient of determination $R^{2}=0.9921$. The high water content static pressure test suggests that the load in the loading direction is the coupled load of the working load of the hydraulic cylinder and the internal stress of the bale. When harvesting wheat stalks with high moisture content, the density parameter of the bale can be appropriately increased while the load parameter of the hydraulic cylinder can be considered unchanged or even reduced. The adjustment of density and load can still ensure the forming quality of the bale.
\end{abstract}

Keywords: baler, rheological properties, wheat stalk, mechanical properties

DOI: $10.25165 /$ j.ijabe. 20211405.6265

Citation: Tang Z, Liang Y Q, Zhang B, Wang M L, Zhang H, Li Y M. Effects of multi-sequence combination forces on creep characteristics of bales during wheat harvesting. Int J Agric \& Biol Eng, 2021; 14(5): 88-99.

\section{Introduction}

As the world's second-largest food crop, the cultivation of wheat is mainly concentrated between $18^{\circ} \mathrm{N}-50^{\circ} \mathrm{N}$. China, Europe and North America are the world's main wheat growing areas, with a total sown area of 219 million hectares in the world. Mechanized high-efficiency operations are no longer the only requirement for wheat harvesting. The recycling and utilization of wheat straw has become a mainstream international trend. The forage in the field needs to be bundled to complete the collection. Wheat straw gradually shifts from agricultural waste to industrial raw materials. Rational use of straw is an important research direction of common concern all over the world.

The structure and composition of wheat have been studied systematically in the fields of ecology and chemistry. The chemical components of wheat caryopsis mainly include starch and wheat protein. Obadi et al. ${ }^{[1]}$ have specifically determined the

\section{Received date: 2020-11-06 Accepted date: 2021-05-05}

Biographies: Yaquan Liang, Master candidate, research interests: intelligent harvesting machinery, Email: 823389273@qq.com; Ben Zhang, Master candidate, research interests: intelligent harvesting machinery, Email: 1035726871@qq.com; Meiling Wang, Master Candidate, research interests: intelligent harvesting machinery, Email: 1131462006@qq.com; Hao Zhang, Master candidate, research interests: intelligent harvesting machinery, Email: 1160387587@qq.com; Yaoming Li, PhD, Professor, research interests: intelligent harvesting machinery, Email: ymli@ujs.edu.cn.

*Corresponding author: Zhong Tang, PhD, Associate Researcher, research interests: intelligent harvesting machinery. School of Agricultural Equipment Engineering, Jiangsu University, Zhenjiang 212013, Jiangsu, China. Tel: +86511-88797338, Email: tangzhong2012@126.com. molecular structure of starch, focusing on the correlation between wheat digestion rate and starch types. Wheat gluten is considered to have wider application value. Liu et al. ${ }^{[2]}$ tried to apply wheat protein to fiber production to expand the application of wheat protein in non-food fields. Jain et al. ${ }^{[3]}$ studied the pathology of wheat rust from the genetic level, using RNA-seq data to identify the miRNA and lncRNA that respond to leaf rust. Other non-leaf green areas of wheat can also undergo photosynthesis. Zhang et al. ${ }^{[4]}$ showed that the non-leaf green area of wheat will increase with the decrease of water supply. Wheat stalks appear as hollow tissues with medullary cavities inside, which is consistent with other cereals. Lignin is the main component of wheat stalks. Karmanov et al. $^{[5]}$ studied the internal lignin by the deposition-diffusion analysis and capillary viscosity method of wheat and found it was a linear polymer.

The research on wheat stalk mostly focuses on the study of its mechanical properties. The mechanical properties of wheat stalks are considered to be an important basis for guiding lodging resistance research and industrial use. $\mathrm{Li}$ et al. changed the water content and loading rate of the stem to test various mechanical stem varieties of wheat, including tensile test, shear test and bending test. This is also a mechanical test method commonly used for biological materials. With the advancement of research, the applied research of wheat stalk has been developed. Naik et al. ${ }^{[6]}$ conducted mechanical tests on wheat stalks and analyzed the chemical composition of the stalks. The main failure modes of straw during mode I failure and mixed failure were analyzed at the same time. The mechanical properties of wheat stalks show that they can be used to make a variety of biological mixtures for other industries. Aksogan et al. ${ }^{[7]}$ conducted compressive strength tests, 
abrasion tests, and freeze-thaw tests on composite materials composed of wheat straw, maize stalks, sunflower stalks and other non-biological materials. Compared with traditional concrete, the radiation shielding properties of materials added with biological straws are significantly improved. In addition, Binici et al. ${ }^{[8]}$ also studied the thermal insulation properties of a mixture of wheat, sunflower stalks and stone materials. The stalk materials are considered to have better thermal insulation properties.

Most of the application researches on wheat stalks involve the compression characteristics of the stalks, and compression is also the main form of damage when the baler bales the wheat. Noel et al. ${ }^{[9]}$ used atomic force microscopy (AFM), instrumented indentation test (IIT) and compression tests to evaluate the mechanical properties of hard and soft wheat varieties with different structural levels at $10 \%$ and $15 \%$ water content. Chougan et al. ${ }^{[10]}$ used separate and mixed pretreatment methods such as hot water, steam and microwave to improve the mechanical properties of stalks, which balances the relationship between water content and wheat compactness and benefits storage of wheat stalks and composite organisms materials.

Based on the research on the mechanical properties of wheat, many scholars have conducted in-depth research on the mechanism of the baler. Tang et al. ${ }^{[11]}$ designed and checked the parameters and structure of the harvesting-bundling integrated machine. The parameters of the formed bale were $40 \mathrm{~cm} \times 50 \mathrm{~cm} \times 54-63 \mathrm{~cm}$ in height, width and length, the bale weight was $22.5-26.0 \mathrm{~kg}$, and the package density was $206-216 \mathrm{~kg} / \mathrm{m}^{3}$. Afzalinia et al. ${ }^{[12]}$ assumed that the bale formed by the baler was an isotropic linear material, and established an analytical model of the three-dimensional pressure distribution in the compression chamber of a large square baler. When the bale is used as a linear material, the elastic modulus and Poisson's ratio can be used to characterize the material properties of the bale. Lecompte et al. ${ }^{[13]}$ used the modulus of elasticity to measure the performance of bales under two baling methods. Molari et al. ${ }^{[14]}$ proposed a physical model of a nonlinear conical spring based on this characteristic, in which the force direction of the spring is the same as the compression direction of the hydraulic cylinder. In addition, the non-linear nature of the bale is also characterized. Koh et al. ${ }^{[15]}$ proposed the stickiness and nonlinearity of straw bales under specific conditions based on the application of straw bales in the construction industry.

Many scholars have carried out a lot of researches on the application level of straw bales. Elastic modulus and stress level are the physical quantities used by most researchers to measure the mechanical properties of straw bales. The parameter design of the baler needs to base on the physical characteristics of the bale under force, but the internal characteristics of the bale under the static pressure state lack relevant research. Moreover, the current research is not comprehensive for the nonlinear research of the bale, and has not yet established an accurate mechanical model for the bale produced by baler. In this paper, the rheological properties are considered to be an important direction of research on the properties of agricultural fiber materials. First, the mechanical properties of the stalks during the threshing process were tested. Based on the test results, the stalk static pressure test and the bale static pressure test were carried out. Moisture content and density were used to study the internal characteristics of the bale as influencing factors. The study of creep properties of the bales can guide the parameter design of the baler in the agricultural harvesting process.

\section{Materials and methods}

\subsection{Analysis of wheat mechanical properties}

Mature wheat is the research object of this article. From the perspective of plant organs, mature wheat is divided into roots, stems, leaves and ears. As shown in Figure 1, the roots of wheat appear as fibrous roots, and the tillering of wheat stalks will generate thick secondary roots at the tiller nodes in the soil ${ }^{[16,17]}$. The main structure of mature wheat leaves includes sheaths and leaves, which are mixed with the stalk after harvest. Wheat is a compound spike-like flaccid, and the head structure includes the cob and the attached spikelets. The growth state of wheat ears determines the yield of wheat.

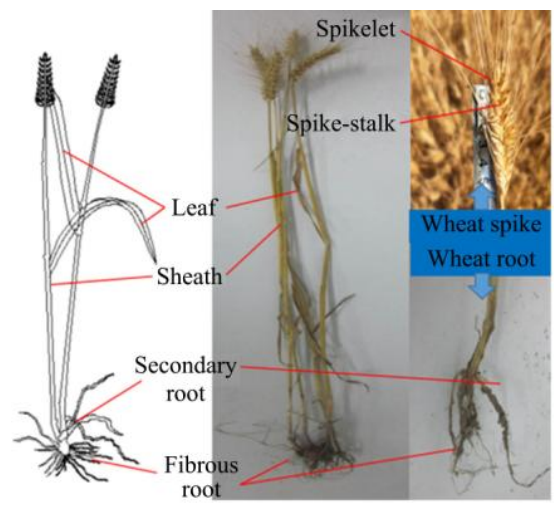

Figure 1 Schematic diagram of wheat structure

Stem is the main research object. Wheat stalk is composed of nodes and internode vascular bundles. Wheat stalks have support, transport, photosynthesis and storage functions. The stalks of wheat are divided into above-ground part and underground part. The stalks of the underground part have secondary roots at the tiller nodes, and the stalks of the above-ground part are covered with leaf sheaths. The stalks of the above-ground part are generally 4-6 nodes, and the structure is similar to that of barley, rice and reed ${ }^{[18]}$. Support and transportation are two main functions of stalks. Wheat stalks can transport water and nutrients to the ears. The vascular bundles inside the stalks are the basis for the stalks to achieve this function ${ }^{[19]}$. The cross-sectional structure of the stalk is shown in Figure 2. The microstructure of the cross-section of the wheat stalk can be clearly observed by a microscope, including the internal medullary cavity, parenchyma, vascular bundles and external mechanical tissues from the inside to the outside. The leaf sheath is located on the outside of the stalk in its natural state, which can enhance the mechanical strength of the plant. The existence of vascular bundles and hollow stalks makes the weight of wheat stalks lighter and easy to be compressed during bundling operations $^{[20]}$.

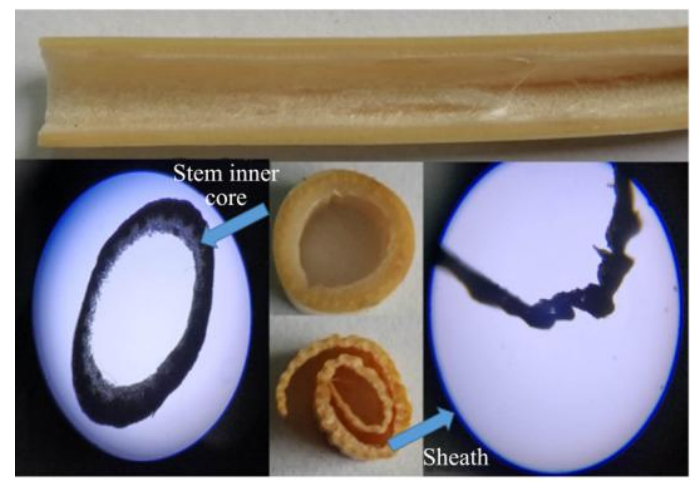

Figure 2 Schematic diagram of the cross-sectional structure of the stem 
The structural characteristics of wheat stalks are considered to be one of the reasons for easy compression and bundling. Before exploring the mechanical characteristics of straw bales, it is necessary to study the damage mode and mechanical strength of wheat plants. Tensile test, compression test and bending test can measure the corresponding mechanical properties of wheat stalks, and the elastic modulus of the stalks can be derived through equations.

When performing tensile test and compression test, the direction of loading coincides with the axis of the stem, and the calculation of tensile strength is shown in Equation (1). Bringing in the force when the stalk is broken and the cross-sectional area of the broken place, the result is the tensile and compressive strength of the stalk ${ }^{[21,22]}$.

$$
\sigma(x)=\frac{F(x)}{A(x)}
$$

where, $x$ is direction matrix; $\sigma(x)$ is the tensile strength or compressive strength function of the stalk, $\mathrm{MPa} ; F(x)$ is the resultant force function of the external force on the stalk, $\mathrm{N} ; A(x)$ is the cross-sectional area function of the stalk, $\mathrm{mm}^{2}$.

The cross-sectional area function of the stalk is usually approximate to the area of a ring, which is mainly determined by the outer diameter and wall thickness of the stalk. Therefore, the theoretical cross-sectional area function of the stalk is shown in Equation (2). Based on the cross-sectional area, the elastic modulus of the material is shown in Equation (3).

$$
\begin{gathered}
A=\frac{\pi}{4}\left(D^{2}-(D-2 \delta)^{2}\right) \\
E=\frac{F l}{\Delta l A}
\end{gathered}
$$

where, $D$ is the outer diameter of the stalk, mm; $\delta$ is the wall thickness of the stalk, mm; $E$ is the elastic modulus, MPa; $F$ is the external force, $\mathrm{N} ; l$ is the length of the material and $\Delta l$ is the length variation, $\mathrm{mm}$.

The cross-sectional area calculation formula can only be substituted into the calculation when the stalk section is not damaged $^{[23,24]}$. However, during the tensile test, the cross-sectional area of the wheat stalk is deformed under the clamping action of the clamp and the stretching action of the instrument. In particular, mature wheat has low moisture content, and the brittle stalks may even undergo axial chipping during the test. In this case, using Equation (2) and Equation (3) to calculate the tensile strength and elastic modulus of the stalk has a significant error. Compression testing is considered to be a better measure for calculating the modulus of elasticity ${ }^{[25,26]}$.

\subsection{Experimental design}

\subsubsection{Basic mechanical test design}

The growing areas of wheat mostly belong to temperate continental climate with less precipitation. Mature wheat plants have lower water content. The use of a combine harvester to harvest wheat is shown in Figure 3. The combine harvester cuts the wheat plant about $5 \mathrm{~cm}$ above the ground, and completes the wheat harvest by cutting, threshing, cleaning and transportation. The wheat stalks after threshing are discharged from the combine harvester, and most of the stalks can be kept intact.

In this paper, the test device for testing the mechanical properties of wheat stalks is Edgar 0824 tensile-compression testing machine (Yueqing Aidebao Instrument Co., China). This testing machine has matching analysis software that can dynamically read the test data. The parameters of Edgar 0824 tensile-compression testing machine are listed in Table 1.

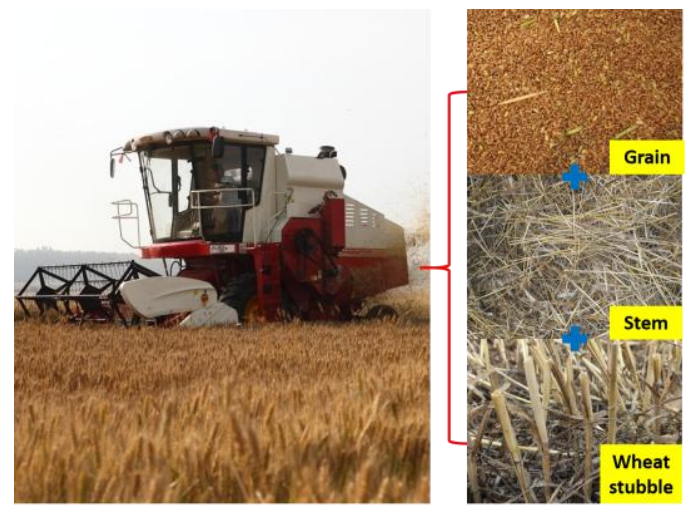

Figure 3 Wheat harvesting and separation

Table 1 Parameters of Edberg 0824 push-pull testing machine

\begin{tabular}{lc}
\hline \multicolumn{1}{c}{ Parameters } & Value \\
\hline Model & HP-200 \\
Test distance accuracy & $0.1 \mathrm{~mm}$ \\
Test force accuracy & $0.5 \%$ \\
sensors & Built-in pressure sensor \\
Test distance range & $0.1-180 \mathrm{~mm}$ \\
Loading range & $\pm 20 \mathrm{~kg}$ \\
PC interface & RS232C standard port or USB port \\
Operating temperature & $-20-60^{\circ} \mathrm{C}$ \\
\hline
\end{tabular}

When testing with Edgar 0824 tensile-compression testing machine, a suitable fixture is selected and the test sample is clamped on the testing machine to ensure that the sample does not slip during the test. The test can be carried out after the zero calibration. Based on the fixture and indenter of the testing machine, various forms of mechanical performance testing can be achieved.

Like most gramineous plants, the stalk of wheat is divided into several segments by knots. The physical properties of the stalk are affected by the knots. Therefore, the tensile test of the stalk is under the condition that whether it contains outer leaf sheaths and whether it contains stalk knots. The stalk sampling length is uniformly set to $50 \mathrm{~mm}$, and the samples are divided into stalk outer skin samples, ordinary stalk samples, stalk-containing samples and stalk inner core samples.

The wheat stalk was clamped by a two-point clamp during the tensile test, and the clamping method is shown in Figure 4. The two-point clamp controls the stem sample longitudinally and locks the chuck to prevent slippage. The loading process maintains a constant speed to ensure the validity and authenticity of the test data. After the software is started, the test data can be recorded in real time and the test curve can be drawn automatically.

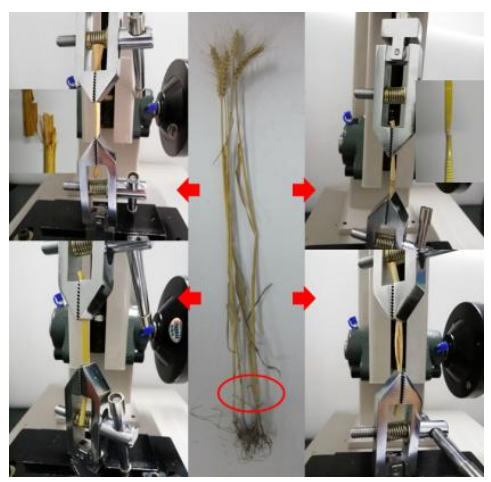

Figure 4 Stem two-point stretching clamping 
In mechanical engineering, the line of action of the resultant force of external forces is often coincident with the axis of the rod when the rod is subjected to compression testing. When the target is wheat stalk, only axial compression of the stalk is insufficient. Compared with metal materials, wheat stalks have more complex structural characteristics and growth patterns. When the compression test is performed, the compression test of wheat needs to be designed in two directions, axial and radial. The length of the wheat stalk sample is also set to $50 \mathrm{~mm}$, which is consistent with the sample design of the tensile test ${ }^{[27,28]}$.

During axial compression, it is divided into ordinary stalk compression test, stalk inner core compression test and stalk-containing compression test. The stalk position is arranged in the middle of the sample. The radial compression test of ordinary stems and the compression test of stem knots are radial test items ${ }^{[29]}$. The sample for the radial compression test of stem knots is to take the undamaged stem knots and remove the stems on both sides. The sample preparation is shown in Figure 5. After the wheat is threshed by the combine harvester, most of the ears are still connected to the stalk. A set of compression tests are also set for the wheat ears.

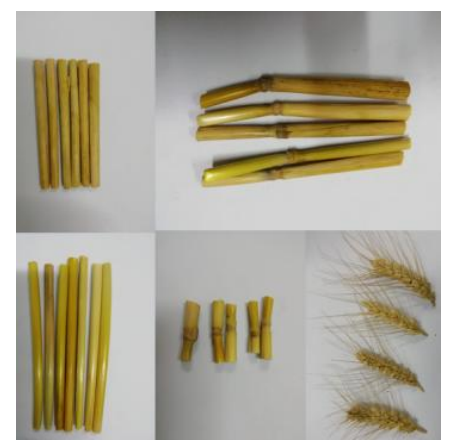

Figure 5 Compression test sample

The compression test needs to replace the fixture of the testing machine. The cylindrical indenter can meet the requirement of the compression test of the stalk, and the indenter with a larger diameter is used for ear compression ${ }^{[30]}$. The fixture and clamping method of the compression test are shown in Figure 6. The compression test does not need to clamp and fix the sample in advance, but it is necessary to zero the test machine before the test. The method of data collection is the same as the tensile test.

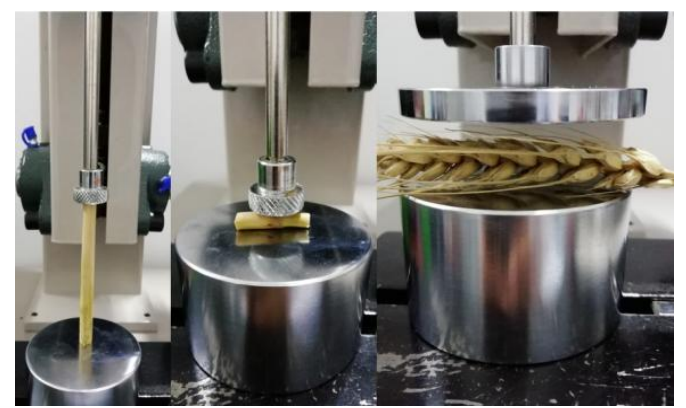

Figure 6 Schematic diagram of compression test clamping

\subsubsection{Stem static pressure test design}

The stalk is the main load-bearing part of the bale, and the creep characteristics of the bale are closely related to the stalk. It is necessary to perform a static pressure test on the stalk. The axial compression test of the stem allows the ultimate compression load to be obtained, and the threshold of the static pressure test load is set below the ultimate load ${ }^{[31,32]}$. A cylindrical indenter was used to fix and load the stalks, and the stalks with a diameter of about $4 \mathrm{~mm}$ and a length of $50 \mathrm{~mm}$ were prepared as samples. As shown in Figure 7, in order to ensure that the stem does not fail on both sides due to clamping, glue and wooden sticks are used to reinforce both sides of the stem sample.

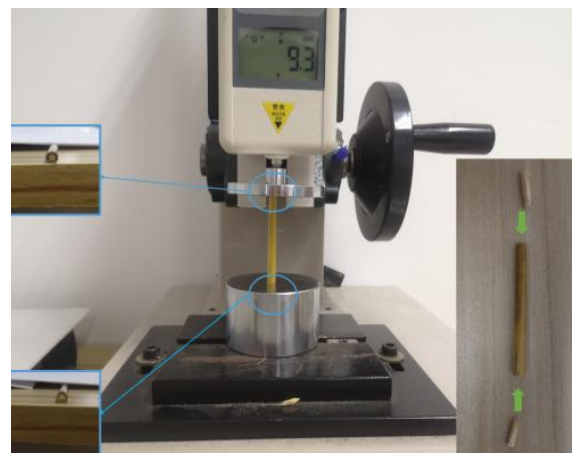

Figure 7 Stem static pressure clamping

In addition to the compression test of a single stalk sample, a $10 \times 10$ stalk module static pressure test was designed to try to observe the uniformity of a large number of stalk samples below the ultimate load level. As shown in Figure 8, the stalks are treated with glue, and the size of the stalk module made is $35 \mathrm{~mm} \times$ $40 \mathrm{~mm} \times 50 \mathrm{~mm}$ in length $\times$ width $\times$ height. Compared with a single stalk, the mechanical properties of the stalk module are significantly improved. The static pressure tests in three directions have been used to study the load-bearing capacity of the stalk module. The initial load of the static pressure is set at 200-300 N, and the creep law of the stalk sample and the stalk module can be judged by observing the change curve of the indenter load with time.

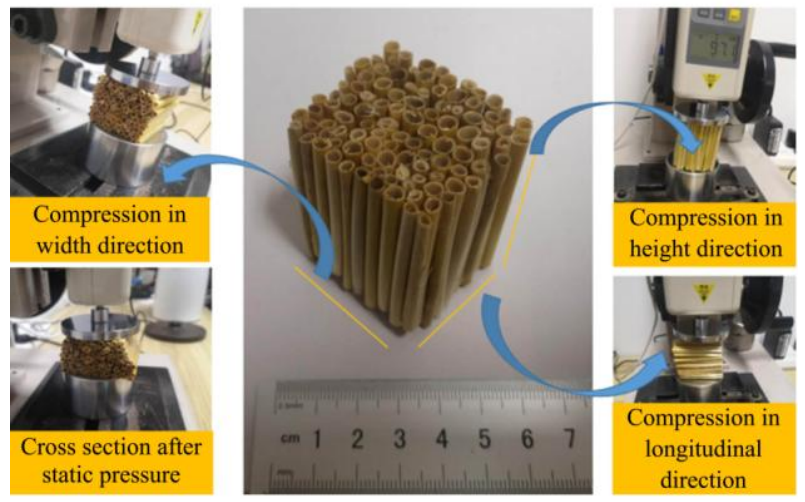

Figure 8 Compression test of stalk module

\subsection{Working principle of the baler}

The baler mainly picks up and bales the leached material produced by the combine harvester, and turns the straw scattered in the field into a square or cylindrical forage block that is convenient for transportation. According to the shape of the bale, the baler is mainly divided into square baler and round baler. The working mechanism of the baler includes a picking mechanism, a crimping mechanism, a knotter and a baling mechanism. When the baler is working, the picking mechanism picks up the grass material in the field and transports it to the grass storage cavity through the conveying device. The piston device compacts the grass material in the grass storage cavity and forms a regular shape. After the compression is completed, the forage is cut off and tied by a knotter. The discharging device discharges the finished product out of the machine body.

The mechanical analysis and model establishment of forage could guide the working parameters setting of baler. As shown in Figure 9, the harvesting and baling work can be completed by the harvesting and baling integrated machine. The stubble height in 
the harvested field is generally about $5 \mathrm{~cm}^{[33,34]}$. The clear distribution of wheat stubble indicates that there is little straw left in the field. The operation of the baler can reduce the scattered straw and collect the straw efficiently.

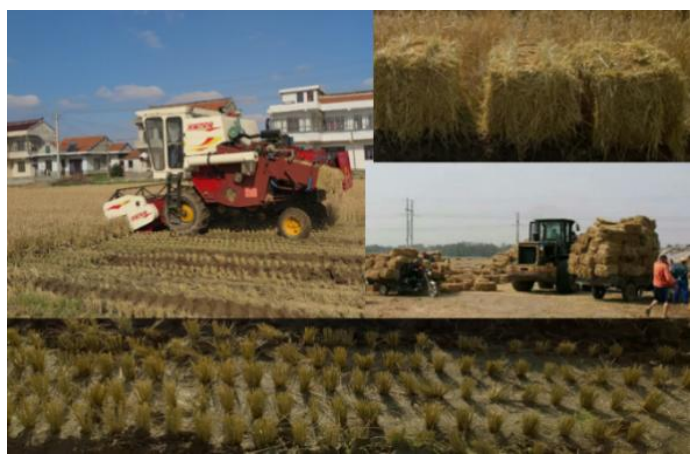

Figure 9 Working process of the harvesting-baler integrated machine

This article takes the square tying machine as the object for research. As shown in Figure 10, compared with round baler, the crimping mechanism of the square baler is mainly composed of feeding fork, hydraulic piston and compression chamber. The density of the bale is uniform, and the density level is higher than that of the bale under the operation of the round baler. The density of straw bales is usually $100-180 \mathrm{~kg} / \mathrm{m}^{3}$, and the high-density baling mechanism can reach $350-500 \mathrm{~kg} / \mathrm{m}^{3}$ for special purposes. Different density levels not only require different parameters for the organization, but also have different requirements for the properties of forage.

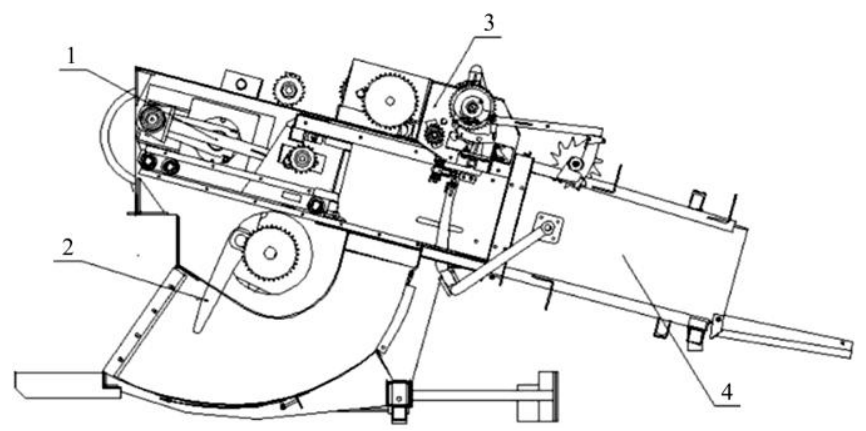

1. Hydraulic piston 2. Feed fork 3. Knotter 4. Compression chamber Figure 10 Diagram of square baler structure

\subsection{Bale characteristics and theoretical models}

The bale is formed by collecting and compressing forage mainly composed of wheat stalks, and it is formed by the rolling and pressing mechanism of the baler. The production of straw bales is to form the forage through a certain period of compression. The mechanical properties of straw bales are significantly related to the physical properties of wheat stalks, but there are also significant gaps. The theoretical analysis and mechanical testing of wheat stalks are the basic research of straw bales. During the production process, the production of straw bales requires guidance by intuitive parameters.

Creep is an inevitable phenomenon after the bale is formed. When the stalks are continuously compressed in the grass storage cavity of the baler, the internal stress of the forage does not remain constant. The internal stress status of the forage cannot be calculated only from the instantaneous force characteristics. The stress of the bale also needs to be considered before the test. Creep theory believes that under the condition of constant stress, as the external load continues to exist, the internal stress will change with the strain, and the stress will change with time. As shown in
Figure 11, the creep of the material is considered to have three stages, including initial creep, steady-state creep and accelerated creep. The external load required for creep triggering is much smaller than the ultimate load of the bale. Almost when the hydraulic cylinder forage applies a compressive load, the bale begins to creep.

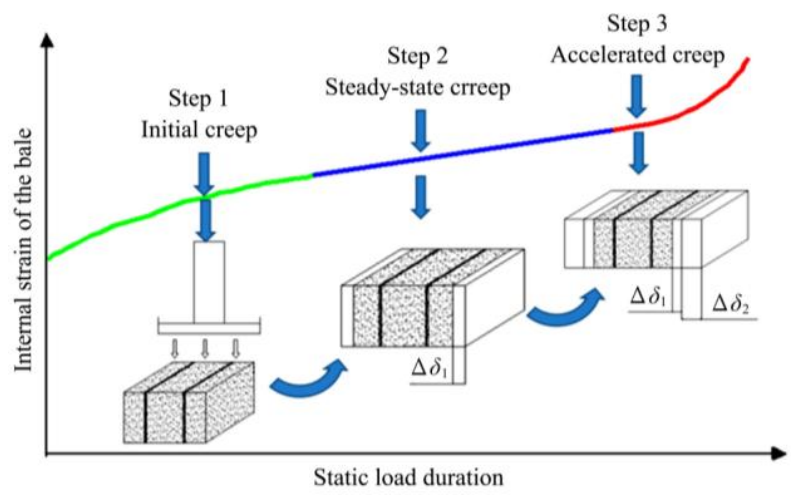

Figure 11 Theory and process of bale forming creep

After the bale is compressed, the internal stress change is not completely reversible, and the stalk has partial plastic deformation under continuous stress. The theory of creep aftereffect believes that the phenomenon of creep is actually plastic aftereffect, which is an irreversible process. The function of stress and strain can express the creep process. The calculation formula is shown in Equation (4). Strain can be divided into two parts as shown in Equation (5).

$$
\begin{gathered}
\sigma=f(\varepsilon) \\
f(\varepsilon)=\sigma(t)+\int_{0}^{t} K(t-\tau) \sigma(\tau) \mathrm{d} \tau
\end{gathered}
$$

where, $\sigma(t)$ is the initial internal stress of the material, MPa; $\varepsilon$ is the material strain; $t$ is the stress time, $\mathrm{s} ; K$ is the influence coefficient, which refers to the deformation caused by the unit stress in $t$.

The moisture content has a significant effect on the toughness and strength of the stalk, so it is meaningful to use the moisture content as a variable to study the force of the bale. When the harvesting and baling machine is used for operation, the moisture content of the forage is higher than that of the material after swathing. Therefore, it is necessary to analyze the influence of moisture content on the characteristics of bales.

The analogy test is carried out through the isometric bale model to simulate the state of the bale under actual working conditions. Firstly, the forage is compacted and fixed to make the bale into a regular shape. In the sample preparation process, the density of the bale is a variable that needs to be strictly controlled. The density of the bale is calculated by measuring the mass and volume of the bale. Keeping the density of the bale within the range of $100-200 \mathrm{~kg} / \mathrm{m}^{3}$ is to ensure that the bale model used for testing is only significantly different in volume compared with the bale produced by the actual baler. The soaking method is used to prepare wet forage samples.

The density calculation is shown in Equation (6), the conversion between stress and load is shown in Equation (7).

$$
\begin{gathered}
\rho=\frac{m}{V} \\
\sigma=\frac{4 P}{\pi d^{2}}
\end{gathered}
$$

where, $\rho$ is the density of the bale, $\mathrm{kg} / \mathrm{m}^{3} ; m$ is the mass of the forage, $\mathrm{kg} ; V$ is the volume of the beaker, which was set to $200 \mathrm{~mL}$ in the experiment, $\mathrm{m}^{3} ; P$ is the load of the testing machine, $\mathrm{N} ; \sigma$ is 
the average stress, MPa; $d$ is the diameter of the indenter, $\mathrm{mm}$.

Cylindrical indenter $(d=58 \mathrm{~mm})$ was used for testing. The indenter is controlled by the rocker arm on the universal testing machine to compress the sample. The load on the sample is deduced from the stress and the bale volume. When the load of the testing machine reaches the designed test level, the indenter is allowed to stand, and the change of load is recorded with time as the independent variable.

Four experimental groups are designed. The bale density of the three density levels is set as the test variable, respectively 100 , 150 and $200 \mathrm{~kg} / \mathrm{m}^{3}$. The beaker was weighed to $80 \mathrm{~g}$ before the experiment. According to the pre-designed bale density, grass material of corresponding quality was added in the beaker, and the allowable error was within the range of $0.5 \mathrm{~g}$. The result of the weighing is shown in Figure 12. The theoretical masses of the samples of the three densities are $100 \mathrm{~g}, 110 \mathrm{~g}$ and $120 \mathrm{~g}$. Place the beaker under the pressure head, manually control the pressure head to drop to the $200 \mathrm{ml}$ mark of the beaker and let it stand for 3 minutes. In the experiment, the same sample was compressed 10 times and the data was recorded.

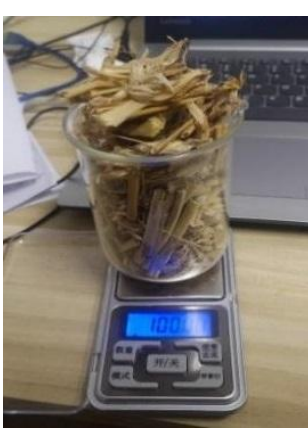

a. $100 \mathrm{~kg} / \mathrm{m}^{3}$

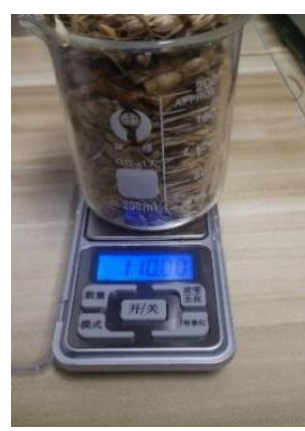

b. $150 \mathrm{~kg} / \mathrm{m}^{3}$

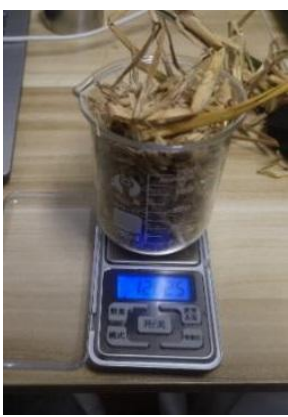

c. $200 \mathrm{~kg} / \mathrm{m}^{3}$

Figure 12 Weighing results of forage mass at three density levels

\section{Results and discussion}

\subsection{Basic mechanics test}

\subsubsection{Tensile test}

The test curve is smoothed by Matlab R2020a, and the test curves under different items are shown in Figures 13. The test curves of different groups showed a trend of rising first and then falling. The rising stage is the loading process, the peak point is where the sample breaks, and the ordinate of the peak point represents the breaking force of the stalk. According to the test data, the peak point range of the tensile test curve of the outer skin of the stem is 15.5-62.9 N. As shown in Figure 13a, the curve drops rapidly after reaching the peak point, at which time the sample has completely broken. In addition, the section of the outer skin sample after stretching was rough. As shown in Figure $13 \mathrm{~b}$, the peak range of the tensile test of the sample containing the stem node is $47.7-87.6 \mathrm{~N}$. The difference is $39.9 \mathrm{~N}$, which is lower than other test items. This indicates that the difference in the strength of stem nodes is not significant.

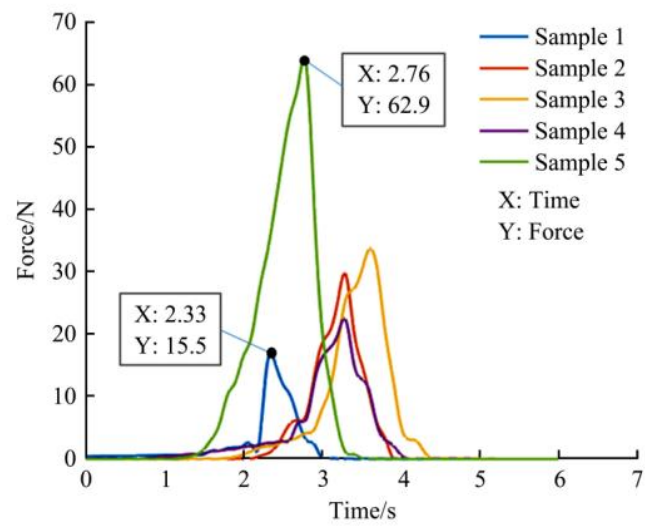

a. Stem outer skin

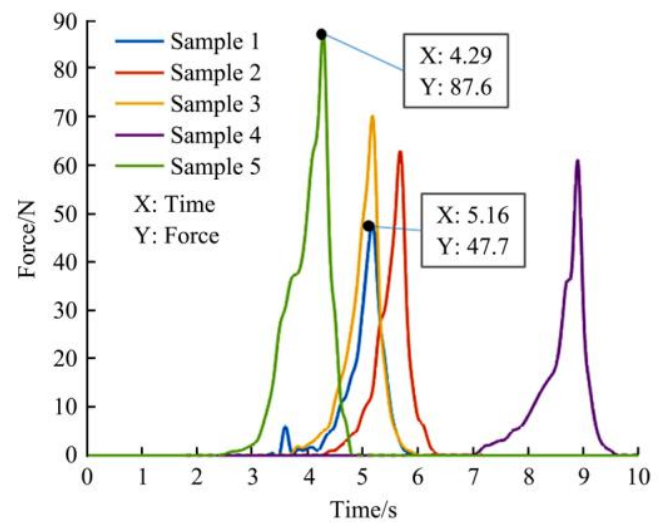

b. Stalk with knots

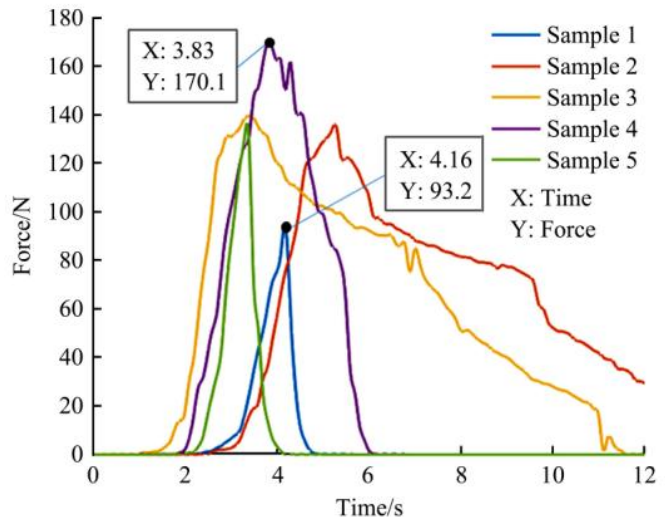

c. Stalk with outer skin

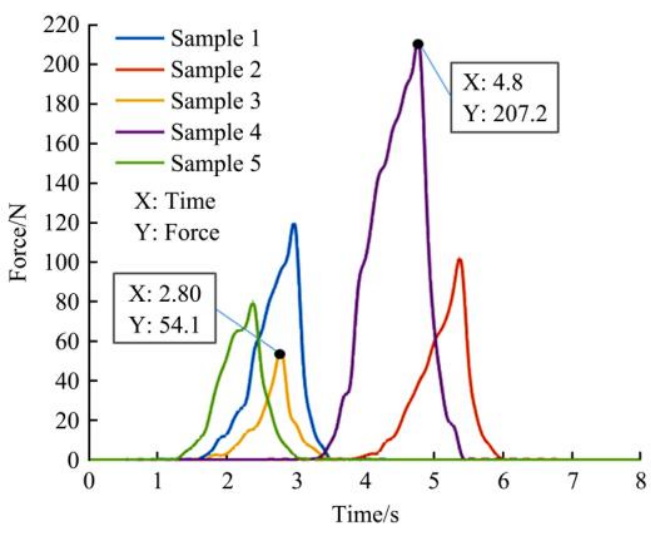

d. Inner core of stalk

Figure 13 Tensile test curve for different parts of wheat straw

As shown in Figure 13c, when the stalk containing the outer skin is stretched, the fracture curve shows a relatively gentle 
fracture process, which indicates that the incomplete fracture occurred during the test. As shown in Figure 13d, the tensile test curve of the inner core of the stalk is similar to that of the outer skin. The fracture also occurs at the peak point of the load, and the fracture is relatively rapid. The peak point range of the tensile test curve of the inner core of the stalk is 54.1-207.2 N.

Equality test is a method in statistics to detect whether there is a significant difference between two data samples ${ }^{[35,36]}$. The sign test method can be used for two sample populations with the same sample size. For the tensile test results of the outer skin and inner core of the stalk, this analysis method can be used. Suppose $\zeta$ and $\eta$ are two continuous populations with distribution functions $F_{1}$ and $F_{2}$, and the two populations each draw samples of $\left(\zeta_{1}, \zeta_{2}, \ldots, \zeta_{n}\right)$ and $\left(\eta_{1}, \eta_{2}, \ldots, \eta_{n}\right)$. Two distributions are independent.

At the significance level $\alpha$, test the hypothesis:

$$
H_{0}: F_{1}(x)=F_{2}(x),-\infty<x<+\infty
$$

For $\zeta_{1}$ and $\eta_{\mathrm{i}}$, there are

$$
P\left\{\zeta_{i}<\eta_{i}\right\}+P\left\{\zeta_{i}=\eta_{i}\right\}+P\left\{\zeta_{i}>\eta_{i}\right\}=1
$$

When using the sign test method for calculations, it is stipulated that: $\left\{\zeta_{i}<\eta_{i}\right\}$ is recorded as "+", and the number of "+" is recorded as $n_{+} ;\left\{\zeta_{i}>\eta_{i}\right\}$ is recorded as "-", and the number of "--" is recorded as $n_{-}$. The statistic that the sign test needs to construct is shown in Equation (10), where $S$ represents the minimum of $n_{+}$and $n$.

$$
S=\min \left(n_{+}, n_{-}\right)
$$

For $n$ and a given significance level $\alpha$, check the sign test table to get the quantile of the distribution that $S$ obeys. So the rule of sign test is obtained: If $S=\min \left(n_{+}, n_{-}\right) \leq S_{\alpha}, H_{0}$ is rejected. $\quad F_{1}$ and $F_{2}$ are considered to be significantly different. If $S=\min \left(n_{+}\right.$, $\left.n_{-}\right)>S_{\alpha}, H_{0}$ is accepted.

The peak points of the two sets of tensile test items were extracted and compared, and the results are listed in Table 2. It is stipulated that the first set of data is greater than the second set of data to be positive, and the number of symbols can be obtained after comparison. The result shows $n_{+}=0$ and $n_{-}=5$. Taking the significance level $\alpha=0.1$ according to the judgment standard of the symbol detection method, it can be obtained that $S=0=S_{\alpha}$. Thus, there is a significant difference between the tensile strength of the outer skin of the stem and that of the inner core of the stem. In addition, according to the difference sign of the sample data, it can be determined that the tensile strength of the inner core of the stalk is significantly greater than that of the outer skin of the stalk.

Table 2 Tensile test peak data of different stalk components

\begin{tabular}{cccc}
\hline Number & Stem outer skin/N & Stem core/N & Symbol \\
\hline 1 & 15.5 & 116.3 & - \\
2 & 29.5 & 99.2 & - \\
3 & 33.6 & 54.1 & - \\
4 & 22.2 & 207.2 & - \\
5 & 62.9 & 78.2 & - \\
\hline
\end{tabular}

The peak point of ordinary stalk tensile test force is in the range of 93.2-170.1 N (Figure 13c). The tensile strength is mainly related to the inner core of the stalk, but the existence of the outer skin will change the breaking law of the stalk. For stalks with knots, the sample break position appears at the knots. The knot structure of the wheat stalk is different from the hollow structure of the stalk. The tensile test shows the mechanical difference between the two parts.

\subsubsection{Compression test}

The test results of the compression test items are peak-extracted, and the data obtained are listed in Table 3. The compression test is considered to be a more accurate way to calculate the elastic modulus of the stalk. Using the mean value of the breaking force of the intact stem and the inner core of the stem to calculate, it can be obtained that the elastic modulus of the inner core sample is 8.24 MPa, and the elastic modulus of the intact stem sample is $7.59 \mathrm{MPa}$. Although the average load of the inner core of the stalk is $52.9 \mathrm{~N}$, which is lower than the $67.2 \mathrm{~N}$ of the intact stalk, the elastic modulus is higher than that of the intact stalk sample considered as a composite material.

Table 3 Compression test peak value

\begin{tabular}{lccccc}
\hline \multicolumn{1}{c}{ Compressed test items } & \multicolumn{5}{c}{ Peak value/N } \\
\hline Complete stalk test & 54.3 & 65.4 & 104.2 & 62.0 & 49.9 \\
Stem core test & 52.0 & 58.1 & 77.4 & 33.2 & 43.6 \\
Stem knot radial test & 187.6 & 117.2 & 106.2 & 96.8 & 89.2 \\
Wheat ear compression test & 154.6 & 103.3 & 97.6 & 122.1 & 94.8 \\
\hline
\end{tabular}

One-way analysis of variance is used to determine whether there are significant differences between multiple sets of data. The sum of squares of the total deviation of the obtained experimental data is fixed, and the calculation formula is shown in Equation (11). The total sum of squares of deviations is composed of two parts: the sum of squares of deviations within the sample group and the sum of squares of deviations between sample groups. The calculation formulas are shown in Equation (12) and Equation (13). The relationship among these three deviations is shown in Equation (14).

$$
\begin{gathered}
S_{T}=\sum_{i=1}^{r} \sum_{j=1}^{n_{i}}\left(x_{i j}-\bar{x}\right)^{2} \\
S_{e}=\sum_{i=1}^{r} \sum_{j=1}^{n_{i}}\left(x_{i j}-\bar{x}\right)^{2}=\sum_{i=1}^{r} n_{i} S_{i}^{2} \\
S_{A}=\sum_{i=1}^{r} n_{i}\left(\overline{x_{l}}-\bar{x}\right)^{2}=\sum_{i=1}^{r} n_{i}\left(\overline{x_{l}}\right)^{2}-n(\bar{x})^{2} \\
S_{T}=S_{e}+S_{A}
\end{gathered}
$$

where, $i$ represents the $i^{\text {th }}$ groups, and $j$ represents the $j^{\text {th }}$ elements in the group; $S_{T}$ is the sum of squares of total deviations; $S_{e}$ is the sum of squares of deviations within a group, and $S_{A}$ is the sum of squares of deviations between groups; $r$ is the number of groups; $n_{i}$ is the number of samples in each group, and $S_{i}$ is the standard deviation of each group of samples; $\bar{x}$ is the sample mean of the population.

The pivot variable needs to be constructed to evaluate the measured test data. The constructed statistic is shown in Equation (15), where $(n-r)$ is the degree of freedom of $S_{e}, n$ is the number of sample population, $(r-1)$ is the degree of freedom of $S_{A}$, and $r$ is the number of groups. The statistic $F(r-1, n-1)$ obeys the $F$ distribution with degrees of freedom $(r-1, n-1)$.

$$
F(r-1, n-r)=\frac{S_{A} \cdot(n-r)}{S_{e} \cdot(n-r)}=\frac{\overline{S_{A}}}{\overline{S_{e}}}
$$

To determine whether there are significant differences between groups, the statistic $F(r-1, n-1)$ needs to be calculated. The summary of statistics for one-way analysis of variance is listed in Table 4. The inspection method is a one-sided inspection and a right inspection.

Table 4 Summary of statistics for one-way analysis of variance

\begin{tabular}{cccccc}
\hline $\begin{array}{c}\text { Source of } \\
\text { Variance }\end{array}$ & $\begin{array}{c}\text { Sum of } \\
\text { squares }\end{array}$ & $\begin{array}{c}\text { Degree of } \\
\text { freedom }\end{array}$ & $\begin{array}{c}\text { Mean deviation } \\
\text { sum of squares }\end{array}$ & $\begin{array}{c}\text { Pivot } \\
\text { variable }\end{array}$ & $\begin{array}{c}\text { Critical } \\
\text { value }\end{array}$ \\
\hline Among groups & 16776.7 & 3 & 5592.2 & 7.6 & 3.1 \\
Within group & 11685.6 & 16 & 730.3 & & \\
\hline
\end{tabular}


There are significant differences between different compression test items, which indicates that the strength of different parts of wheat stalk is different, and the damage form is also different. The stress form of the stem in the threshing drum is complex. The plant will be squeezed in the gap between the concave plates of the threshing drum. Therefore, the compression test can simulate the stress state of wheat when passing through the threshing gap, and establish the foundation for further study of the properties of threshing products.

After the compression test, the status of the stalk sample and the ear head sample are shown in Figure 14, and the normal stalk compression test curve is shown in Figure 15. The failure mode of the stalk on the testing machine is bending. The stalks are not easy to break under the compression test, which is consistent with the phenomenon that most of the stalks are long stalks when the wheat is harvested. The ear head can achieve a certain threshing effect under the squeezing action of pressure head, and the main structure of the ear head is not damaged. In addition, the stalk samples with knots in the middle of the stalk were also used for the compression failure test. The results showed that all the bending points of the samples existed at the knots. The mechanical gap between the stem and the knot is the reason for this result.

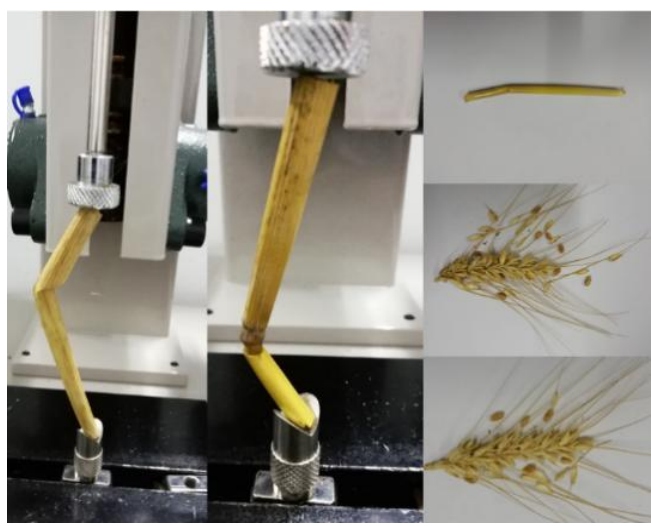

Figure 14 Sample status after compression

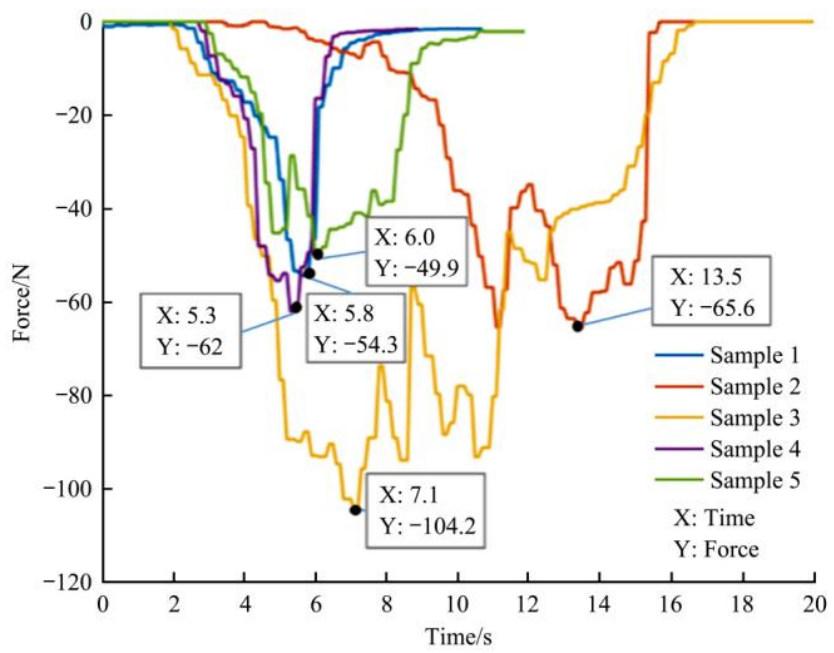

Figure 15 Stalk compression test curve

\subsubsection{Stem static pressure test}

The static pressure test curve of a single stalk is shown in Figure 16. The negative sign of the load value indicates the direction of the load and has no mathematical meaning. The tested static initial load is all lower than $67.2 \mathrm{~N}$, which is the average breaking force of radial compression. Samples that were not broken are considered reasonable in the test. The load fluctuates greatly in the $0-25 \mathrm{~s}$, which is the loading process. The smooth curve after $25 \mathrm{~s}$ represents the static pressure process. The 25-50 $\mathrm{s}$ interval is defined as the fast return phase, during which the load drops rapidly. The interval after $50 \mathrm{~s}$ is defined as the linear return phase. It is worth noting that there is no sudden load change during the static pressure process.

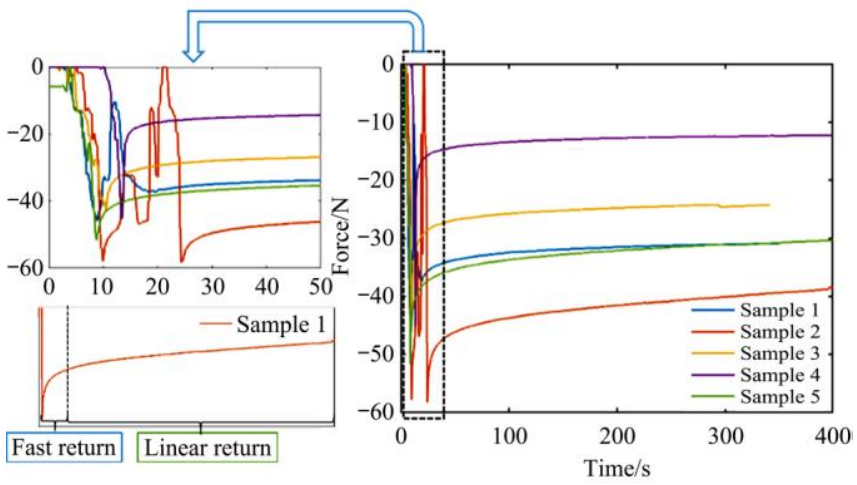

Figure 16 Stem axial static pressure test curve for a single stalk

Under the preset load, no stem fails during the static pressure process, but this does not mean that it does not break during a long loading time. The continuity of the load curve shows that there is no structural failure inside. The load of overall return value is between 14.9-27.7 N. The load of linear return is between 1.3$5.1 \mathrm{~N}$, and the specific return values are listed in Table 5. The load value recovered in the fast return stage accounts for a relatively large portion, while the highest proportion of linear return was $26.3 \%$.

Table 5 Load return value of the single stem static pressure test in different stage

\begin{tabular}{ccccc}
\hline $\begin{array}{c}\text { Sample } \\
\text { number }\end{array}$ & $\begin{array}{c}\text { Fast return } \\
/ \mathrm{N}\end{array}$ & $\begin{array}{c}\text { Linear } \\
\text { return/N }\end{array}$ & $\begin{array}{c}\text { Proportion of } \\
\text { linear return }\end{array}$ & $\begin{array}{c}\text { Overall } \\
\text { return/N }\end{array}$ \\
\hline 1 & 12.7 & 2.2 & $14.8 \%$ & 14.9 \\
2 & 14.3 & 5.1 & $26.3 \%$ & 19.4 \\
3 & 14.7 & 2.1 & $12.5 \%$ & 16.8 \\
4 & 26.4 & 1.3 & $4.7 \%$ & 27.7 \\
5 & 18.2 & 3.2 & $15.0 \%$ & 21.4 \\
\hline
\end{tabular}

The static pressure test of the stalk module can amplify the mechanical properties of the stalk, and higher carrying capacity can be used to analyze the multi-dimensional mechanical properties of the stalk. As shown in Figure 17, $35 \mathrm{~mm} \times 40 \mathrm{~mm} \times 50 \mathrm{~mm}$ is the initial size of the stalk module. After static pressure, there is no significant change in the height direction, the width becomes $29.37 \mathrm{~mm}$, and the length becomes $50.03 \mathrm{~mm}$. The increase in length and decrease in width are similar to the normal strain of the bale in the direction in which the load is applied during compression. The restraint of the storage bin prevents the internal stress of the bale from forming a normal strain, and the load in the loading direction becomes coupled load between the working load of the hydraulic cylinder and the internal stress of the bale.

\subsection{Bale mechanics test}

\subsubsection{Dry forage bale creep characteristics test}

Forage curves for the three density levels are shown in Figure 18 , and similar curve characteristics can be observed. The trend of the load return is divided into the early fast return stage and the late slow return stage. The upper limit of the initial load increases with the increase of the sample density, which are $29.6 \mathrm{~N}, 91.5 \mathrm{~N}$ and 184.2 N, respectively (Figure 18). The upper limit of the initial load is shown in the first compression test. There is a sudden load change phenomenon in the smooth section of the curve, but it only appears once for $200 \mathrm{~kg} / \mathrm{m}^{3}$ sample, which is significantly reduced compared to the other two groups. 
Figure 19 shows the compression test load-time curve with a density of $150 \mathrm{~kg} / \mathrm{m}^{3}$. The first set of data was used for analysis due to its typical characteristics. A negative value on the vertical axis indicates that the direction of the force on the indenter is upward, and the horizontal axis time shows that the loading time is over 3 minutes. The load curve presents a rule of change that first rises and then falls. The rapid increase stage is the loading process of the tension press. The descent process is long and slow, and the descent phase is the main research object. The descending phase of the load can be divided into two phases, about 10-50 s is the rapid descending phase, and the descending range is $22.7 \mathrm{~N}$. The subsequent smooth curve represents the slow descending phase of load, while the load returning $8.7 \mathrm{~N}$ in almost $3 \mathrm{~min}$. However, in the slow descending phase of the load, there was a load step, and the descending amplitude was $4.2 \mathrm{~N}$.

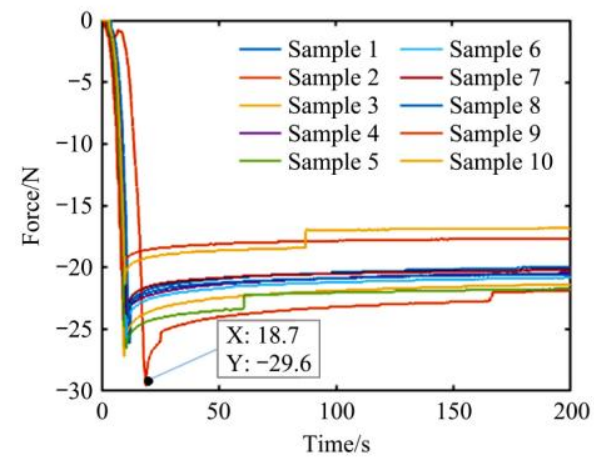

a. $100 \mathrm{~kg} / \mathrm{m}^{3}$

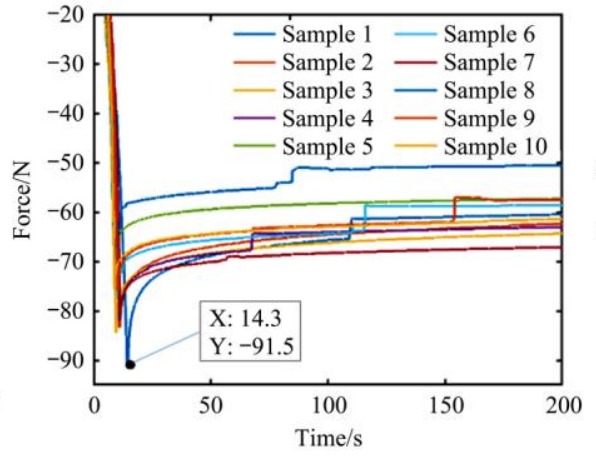

b. $150 \mathrm{~kg} / \mathrm{m}^{3}$

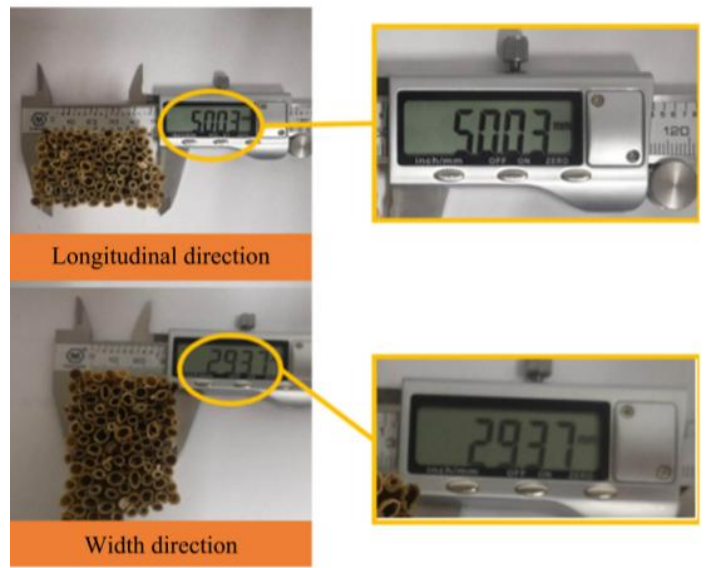

Figure 17 Deformation of the stalk mass after compression

Figure 18 Horizontal static pressure curves for three density samples

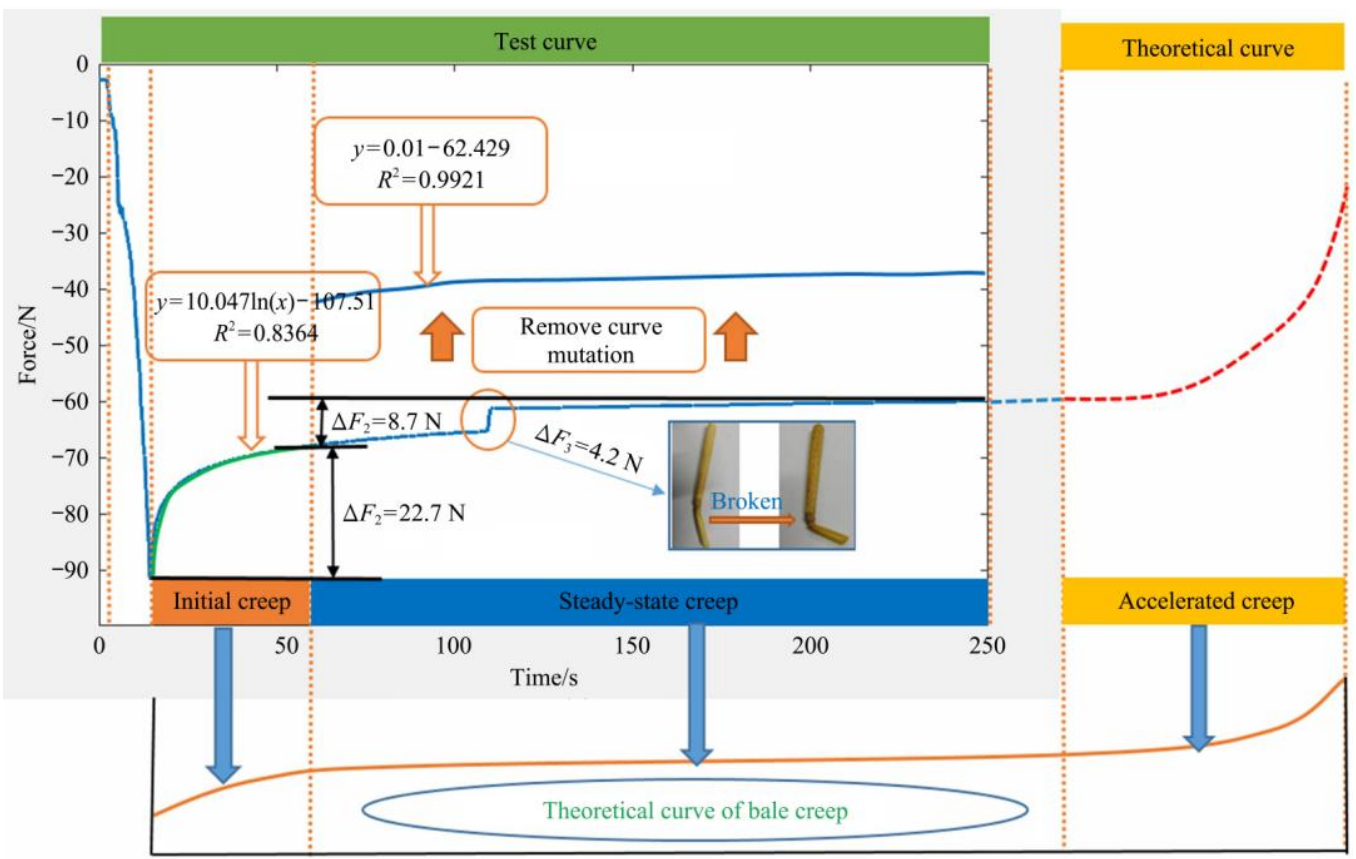

Figure 19 Schematic diagram of bale compression test curve

Combining the compression characteristics of the stalk and the creep theory of the bale, the test results of the bale can be analyzed. The rising phase of the curve is actually the return process of the load. The two stages of the curve correspond to the stress-time curves of initial creep and steady-state creep in creep theory. The initial creep stage is relatively short, and the curve appears as a convex curve, consistent with the changes in the test. The increase of strain reflects the change of the internal organizational structure under continuous stress, and the structural change will inevitably affect the strain of the organization. The strain change process should proceed towards the direction of stress reduction, so the strain should be reduced. During the test, the load continuously reduces when the indenter of the tension-compressor remains stationary, and the internal strain correspondingly reduces, which is consistent with the theory mentioned above.

The obvious load step in the curve can be observed 5 times in Figure $18 \mathrm{~b}$, and the time interval of occurrence is $60-160 \mathrm{~s}$. The load mutation phenomenon is considered to be the internal stalk fracture that causes local stress relaxation in the interior, which in turn affects the overall load. By comparing the changes of the 
wheat samples inside the container before and after compression, it can be also observed that there is a significant difference in the degree of stalk fragmentation. Completely dry stalks can be considered as a brittle material, and structural failure will occur under axial and radial loads.

By comparing the curve of the static pressure and the curve of forage creep, the consistency can be visualized. As shown in Figure 19, the actual experimental process can completely characterize the initial creep stage and part of the steady-state creep stage. The steady-state creep lasts longer. The stress change in the steady-state creep is small and shows a linear change. By fitting and analyzing the experimental data, it can be found that using a linear function to characterize the second piece of data has a high degree of fit, and the coefficient of determination is $R^{2}=$ 0.9921. The first segment of data is fitted with a logarithmic function, and its coefficient of determination is $R^{2}=0.8364$. The accelerated creep stage requires a fatigue test on the bale to be able to be observed, and the experiment cannot be carried out due to limited conditions. However, the stress change law of the continuous load of the bale can also be obtained from the first two stage data by the compression process.

3.2.2 Test of creep characteristics of high water content forage bale

The method of soaking and auxiliary drying makes the dried wheat stalk reach a certain moisture content level, and the moisture content of the wheat stalk can be determined by weighing. The sample used is Zhenmai 168 in Jiangsu, China, and its stem moisture content is $40.4 \%-45.8 \%$. The moisture content of the sample is designed to be slightly higher than that of the actual harvested wheat. The test method is the same as that of the dry stalk. The pressure head drops to the $200 \mathrm{~mL}$ mark of the beaker. The sample weighing and test are shown in Figure 20. The dry sample is $30 \mathrm{~g}$ and the wet sample is $61.46 \mathrm{~g}$. The calculated moisture content of the sample is $51.19 \%$.

The curve obtained from the 10 static pressure tests is shown in Figure 21. Compared with the dry curve, there is no load mutation phenomenon in the steady-state creep stage. The upper limit of the initial load is $59.2 \mathrm{~N}$, which is lower than the upper limit of the same $30 \mathrm{~g}$ forage with a density of $150 \mathrm{~kg} / \mathrm{m}^{3}$. In general, the trend of the high water content forage compression curve and the dry forage compression test curve is still consistent.

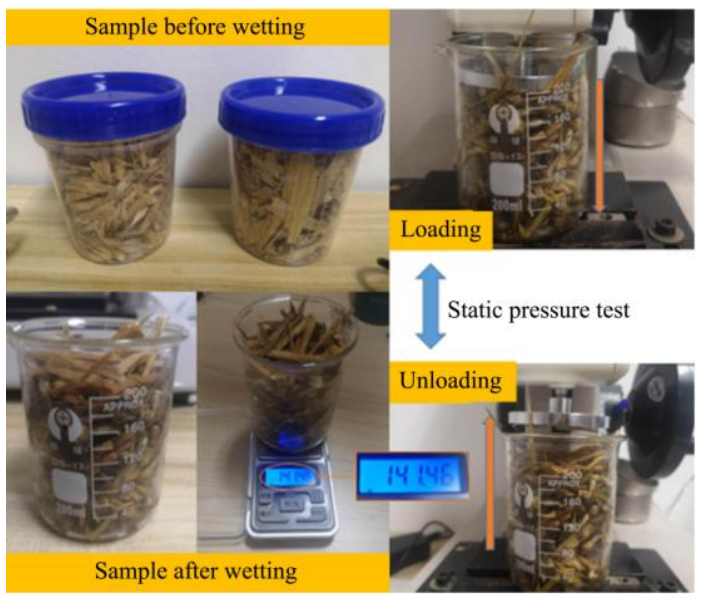

Figure 20 Static pressure test for wet forage

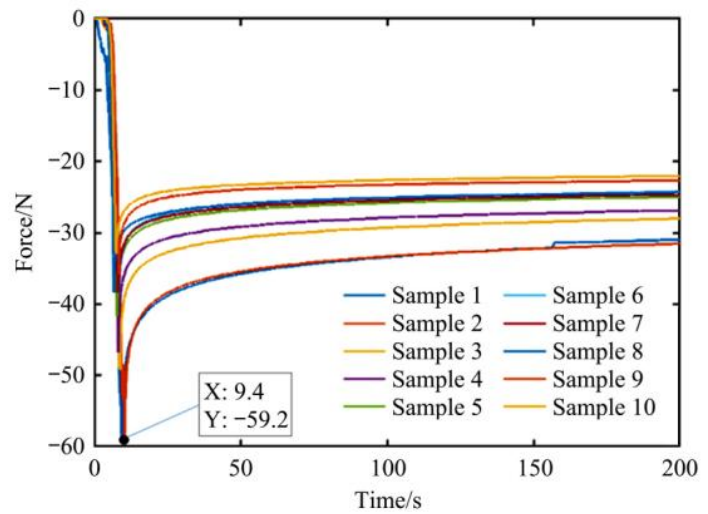

Figure 21 Static pressure test curve of wet forage

The data of the upper limit of the load for the compression test is listed in Table 6. The maximum peak loads of the four tests are 29.6 N, 91.5 N, 184.2 N and 59.2 N, respectively. The maximum load peak value is reflected in the first test, and the curve overlap in the following test is obvious. In subsequent tests, the peak load of the first test was not reached, which suggests that the local recovery characteristics after compression can be reflected.

Table 6 Upper limit of static pressure test load

\begin{tabular}{|c|c|c|c|c|c|c|c|c|c|c|c|}
\hline \multirow{2}{*}{ Test term } & \multicolumn{10}{|c|}{ Peak value of static pressure test/ $\mathrm{N}$} & \multirow{2}{*}{ Average value/ $\mathrm{N}$} \\
\hline & 1 & 2 & 3 & 4 & 5 & 6 & 7 & 8 & 9 & 10 & \\
\hline Dry-100 kg/m 3 & 29.6 & 26.2 & 27.2 & 24.7 & 26.6 & 25.7 & 23.8 & 24.1 & 20.2 & 21.4 & 25.0 \\
\hline Dry- $150 \mathrm{~kg} / \mathrm{m}^{3}$ & 91.5 & 83.3 & 81.5 & 81.9 & 69.5 & 76.7 & 80.8 & 69.4 & 75.8 & 75.7 & 78.6 \\
\hline Dry- $200 \mathrm{~kg} / \mathrm{m}^{3}$ & 184.2 & 176.1 & 156.2 & 130.1 & 139.8 & 119.5 & 124.8 & 134.8 & 117.9 & 113.5 & 139.7 \\
\hline Wet $-150 \mathrm{~kg} / \mathrm{m}^{3}$ & 59.2 & 58.6 & 49.2 & 46.8 & 36.4 & 38.3 & 38.3 & 38.3 & 35.8 & 33.0 & 43.4 \\
\hline
\end{tabular}

After the forage contains water, the internal tissues are softened, especially the mechanical properties of the stalks undergo significant changes. The compression limit reduced, and most of the stalk tissues are broken after the first load. The test curve reflects that there is no load step caused by the stalk fracture in the subsequent static pressure test. The softening of various parts of the forage also causes the upper limit of the load to drop, but it is still higher than the upper limit of the low-density forage. For forages with high moisture content during harvest, the density parameter of the bale can be appropriately increased while the load parameter of the hydraulic cylinder can be considered unchanged or even reduced. Such adjustment can still ensure the forming quality of the bale.

\section{Conclusions}

(1) A variety of stalk samples with a length of $50 \mathrm{~mm}$ were tested for tension and compression. The tensile strength of stem outer skin and stem core is considered to be significantly different at the confidence level of $\alpha=0.1$. The strength of stem core is significantly higher than stem outer skin. The compressive strength of the intact stalk, the inner core of the stalk, the stalk node, and the head of the ear are considered to be significantly different under the confidence level of $\alpha=0.05$. The measured elastic modulus of the intact stalk sample was $7.59 \mathrm{MPa}$, and the elastic modulus of the inner core of the stalk was 8.24 MPa.

(2) The fast return phase and linear return phase can be 
observed in the static pressure test for forage bale. The load return range of the linear phase is between 1.3-5.1 N. The load value recovered in the fast return phase accounts for a relatively large amount, and the load recovery in the linear return phase only accounts for less than $26.3 \%$ of the total recovery value. After the $35 \mathrm{~mm} \times 40 \mathrm{~mm} \times 50 \mathrm{~mm}$ stalk module is subjected to static pressure, the length becomes larger and the width becomes smaller, which is similar to the normal strain in the direction of load application of the bale during compression. The restraint of the storage bin prevents the internal stress of the bale from forming a normal strain, and the load in the loading direction becomes the coupled load between the working load of the hydraulic cylinder and the internal stress of the bale.

(3) The load return law under the static pressure test of dry forage with three density levels of 100,150 and $200 \mathrm{~kg} / \mathrm{m}^{3}$ and wet forage with the density of $150 \mathrm{~kg} / \mathrm{m}^{3}$ accords with the creep aftereffect theory. The use of a linear function to characterize the slow return phase data has a high degree of fit, and the coefficient of determination is $R^{2}=0.9921$. The fast return curve is fitted with a logarithmic function, and the coefficient of determination $R^{2}=0.8364$. The load step phenomenon can be observed in the dry sample, which occurred 3 times, 5 times, and once, respectively. The reason for the load step is related to the breakage of the stem during the static pressure process. A lower load indicates that when harvesting forage with a higher moisture content, the density of the bale can appropriately increase while the load parameters of the hydraulic cylinder can be considered unchanged or even reduced. Such adjustment can still ensure the forming quality of bale.

\section{Acknowledgements}

This research work was supported by National Natural Science Foundation of China (Grant No. 52175235), Single Technology Research and Development Project of Jiangsu Agricultural Science and Technology Independent Innovation Fund (CX(21)3144), Jiangsu Province "Six Talents Peak" High-level Talent Project (Grant No. GDZB-085), and the Open Fund of Jiangsu Key Laboratory of Agricultural Equipment and Intelligent High Technology (Grant No. JNZ201912).

\section{[References]}

[1] Obadi M, Li C, Li Q, Li X, Qi Y, Xu B. Relationship between starch fine molecular structures and cooked wheat starch digestibility. Journal of Cereal Science, 2020; 95: 103047. doi: 10.1016/j.jcs.2020.103047

[2] Liu C, Ma X. Study on the mechanism of microwave modified wheat protein fiber to improve its mechanical properties. Journal of Cereal Science, 2016; 70: 99-107.

[3] Jain N, Sinha N, Krishna H, Singh P, Gautam T, Prasad P, et al. A study of MiRNAs and lncRNAs during Lr28-mediated resistance against leaf rust in wheat (Triticum aestivum L.). Physiological and Molecular Plant Pathology, 2020; 112: 101552. doi: 10.1016/j.pmpp.2020.101552

[4] Zhang Y, Zhang Y, Wang Z, Wang Z. Characteristics of canopy structure and contributions of non-leaf organs to yield in winter wheat under different irrigated conditions. Field Crops Research, 2011; 123(3): 187-195.

[5] Karmanov A, Kanarsky A, Kocheva L, Belyy V, Semenov E, Raachkova $\mathrm{N}$, et al. Chemical structure and polymer properties of wheat and cabbage lignins: Valuable biopolymers for biomedical applications. Polymer, 2021; 220(2): 123571. doi: 10.1016/j.polymer.2021.123571

[6] Naik D, Kiran R. Naive Bayes classifier, multivariate linear regression and experimental testing for classification and characterization of wheat straw based on mechanical properties. Industrial Crops and Products, 2017; 112: 434-448.
[7] Aksogan O, Binici H, Ortlek E. Durability of concrete made by partial replacement of fine aggregate by colemanite and barite and cement by ashes of corn stalk, wheat straw and sunflower stalk ashes. Construction and Building Materials, 2016; 106: 253-263.

[8] Binici H, Aksogan O, Dincer A, Luga E, Eken M, Isikaltun O. The possibility of vermiculite, sunflower stalk and wheat stalk using for thermal insulation material production. Thermal Science and Engineering Progress, 2020; 18: 100567. doi: 10.1016/j.tsep.2020.100567.

[9] Noel B G, Mendez-Mendez J, Arzate-Vazquez I, Calderon-Dominguez G, Daniel Ribotta P. Nano- and micro-mechanical properties of wheat grain by atomic force microscopy (AFM) and nano-indentation (IIT) and their relationship with the mechanical properties evaluated by uniaxial compression test. Journal of Cereal Science, 2019; 90: 102830. doi: 10.1016/j.jcs.2019.102830

[10] Chougan M, Ghaffar S, Al-Kheetan M, Gecevicius M. Wheat straw pre-treatments using eco-friendly strategies for enhancing the tensile properties of bio-based polylactic acid composites. Industrial Crops and Products, 2020; 155: 112836. doi: 10.1016/j.indcrop.2020.112836

[11] Tang Z, Li Y, Cheng C. Development of multi-functional combine harvester with grain harvesting and straw baling. Spanish Journal of Agricultural Research, 2017; 15(1): e0202. doi: 10.5424/sjar/201715110175

[12] Afzalinia S, Roberge M. Modeling of pressure distribution inside the compression chamber of a large square baler. Transactions of the ASABE 2008; 51(4): 1143-1152.

[13] Lecompte T, Le-Duigou A. Mechanics of straw bales for building applications. Journal of Building Engineering, 2017; 9: 84-90.

[14] Molari L, Maraldi M, Molari G. Non-linear rheological model of straw bales behavior under compressive loads. Mechanics Research Communications, 2017; 81: 32-37.

[15] Koh C, Kraniotis D. A review of material properties and performance of straw bale as building material. Construction and Building Materials, 2020; 259: 120385. doi:10.1016/j.conbuildmat.2020.120385

[16] Markowski M, Zuk-Golaszewska D, Kwiatkowski D. Influence of variety on selected physical and mechanical properties of wheat. Industrial Crops and Products, 2013; 47: 113-117.

[17] Wang W, Ge J, Xu K, Gao H, Liu G, Wei H, et al. Differences in starch structure, thermal properties, and texture characteristics of rice from main stem and tiller panicles. Food Hydrocolloids, 2020; 99: 105341. doi: 10.1016/j.foodhyd.2019.105341

[18] Tang Z, Li Y, Zhang B, Wang M, Li Y. Controlling rice leaf breaking force by temperature and moisture content to reduce breakage. Agronomy-Basel, 2020; 10(5): 628. doi: 10.3390/agronomy10050628

[19] Huang J, Liu W, Zhou F, Peng Y. Effect of multiscale structural parameters on the mechanical properties of rice stems. Journal of the Mechanical Behavior of Biomedical Materials, 2018; 82: 239-247.

[20] Leblicq T, Vanmaercke S, Ramon H, Saeys W. Mechanical analysis of the bending behaviour of plant stems. Biosyst. Eng., 2015; 129: 87-99.

[21] Wang J, Zhu J, Lin Q, Li X, Teng N, Li Z, et al. Effects of stem structure and cell wall components on bending strength in wheat. Chinese Science Bulletin, 2006; 51(7): 815-823.

[22] Liu Y, Xie J, Wu N, Ma Y, Menon C, Tong J. Characterization of natura cellulose fiber from corn stalk waste subjected to different surface treatments. Cellulose, 2019; 26(8): 4707-4719.

[23] Cuadrado A, Yanez A, Martel O, Deviaene S, Monopoli D. Influence of load orientation and of types of loads on the mechanical properties of porous Ti6Al4V biomaterials. Materials \& Design, 2017; 135: 309-318.

[24] Alemdar A, Sain M. Biocomposites from wheat straw nanofibers: morphology, thermal and mechanical properties. Composites Science \& Technology, 2008; 68(2): 557-565.

[25] Luo Y, Ni J, Pang D, Jin M, Chen J, Kong X, et al. Regulation of lignin composition by nitrogen rate and density and its relationship with stem mechanical strength of wheat. Field Crops Research, 2019; 241: 107572. doi: 10.1016/j.fcr.2019.107572

[26] Zhou F, Huang J, Liu W, Deng T, Jia Z. Multiscale simulation of elastic modulus of rice stem. Biosystems Engineering, 2019; 187: 96-113.

[27] Khazaeinejad P, Najafizadeh M, Jenabi J, Isvandzibaei M. On the buckling of functionally graded cylindrical shells under combined external pressure and axial compression. Journal of Pressure Vessel Technology, 2009; 132(6): 755-762.

[28] Turner A, Sama M, Bryson L, Montross M. Effect of stem crushing on the uniaxial bulk compression behaviour of switchgrass and miscanthus. Biosystems Engineering, 2018; 175: 52-62. 
[29] Shah D, Reynolds T, Ramage M. The strength of plants: theory and experimental methods to measure the mechanical properties of stems. Journal of Experimental Botany, 2017; 68(16): 4497-4516.

[30] Tang Z, Li Y, Li X, Xu T. Structural damage modes for rice stalks undergoing threshing. Biosystems Engineering, 2019; 186: 323-336.

[31] Fu J, Chen Z, Han L, Ren L. Review of grain threshing theory and technology. nt J Agric \& Biol Eng, 2018; 11(3): 12-20.

[32] Hirai Y, Inoue E, Mori K. Numerical analysis of the reaction force of a single rice stalk undergoing forced displacement. Biosystems Engineering, 2003; 86(2): 179-189

[33] Leblicq T, Vanmaercke S, Ramon H, Saeys W. Mechanical analysis of the bending behaviour of plant stems. Biosystems Engineering, 2015; 129: 87-99.

[34] He P, Li J, Zhang D, Wan S. Optimisation of the harvesting time of rice in moist and non-moist dispersed fields. Biosystems Engineering, 2018; 170: $12-23$.

[35] Walters W. Survey design, sampling, and significance testing: Key issues. Journal of Academic Librarianship, 2021; 47(3): 102344. doi 10.1016/j.acalib.2021.102344

[36] Zhang G, Christensen R, Pesko J. Parametric boostrap and objective Bayesian testing for heteroscedastic one-way ANOVA. Statistics \& Probability Letters, 2021; 174: 109095. doi: 10.1016/j.spl.2021.109095 